\title{
Plant Regeneration System for Osbeckiaoctandra (L.) DC: A Valuable Medicinal Plant
}

\author{
Nagahatenna, D.S.K. ${ }^{1} \&$ Peiris, S.E. ${ }^{2}$ \\ dilu.nagahatenna@adelaide.edu.au, sriyani.p@sliit.lk \\ ${ }^{I}$ School of Agriculture, Food and Wine, University of Adelaide, Waite Campus, Glen Osmond, SA \\ 5064, Australia \\ ${ }^{2}$ School of Natural Science, Faculty of Humanities and Sciences, SLIIT, Malabe, Sri Lanka
}

\begin{abstract}
Osbeckiaoctandra (HeenBovitiya), which is one of the most valuable ayurvedic medicinal and ornamental plants in Sri Lanka, is now threatened due to its overexploitation from their natural habitat. In order to produce high quality, disease-free and genetically identical plant materials in large scale, we developed a highly efficient in vitro clonal propagation system using leaf explants. The effects of three different concentrations of plant growth regulators (6-benzylaminopurine (BAP), 1-naphthaleneacetic acid (NAA), kinetin and incubation conditions on plant regeneration were investigated. Plant growth parameters were analyzed in 15 biological replicates using one-way ANOVA. Present study revealed that the highest number of shoots per leaf explant with $92.4 \%$ shoot induction rate was achieved when young mature leaf explants were cultured on Murashige and Skoog (MS) medium supplemented with $3 \mathrm{mg} / \mathrm{L}$ BAP and $0.5 \mathrm{mg} / \mathrm{L}$ NAA and incubated under dark conditions. When microshoots were separated and subcultured onto hormone-free MS medium containing high sugar content (4\%), rapid shoot multiplication and a vigorous root development was detected under light conditions. The in vitro grown plantlets were successfully acclimatized and $89 \%$ of the regenerated plantlets survived. Our novel clonal propagation system will open new avenues for mass propagation of $O$. octandra plants for the pharmaceutical industry and improving their medicinal and ornamental characteristics through biotechnological tools.
\end{abstract}

Keywords: BAP, Kinetin, Micropropagation, NAA, Osbeckiaoctandra

\section{Introduction}

As a tropical country, Sri Lanka has an extensive diversity of medicinal plants. Over 1400 natural herbs are currently being used in Sri Lankan indigenous systems of medicine such as Ayurvedha and Deshiya Chikitsa to cure various ailments (Napagoda et al., 2018; Napagoda et al., 2019). Even though, over the past decade, the significance of the therapeutical value of medicinal plants and plant-based formulations are largely acknowledged, so far, limited attempts have been made to prevent those valuable medicinal plants being extinct in their natural habitats. So far, large quantities of medicinal plant materials have been sourced from the wild and this unsustainable exploitation has 
identified as a major threat for most of the native medicinal herbs. Therefore, there is an urgent need to develop alternative strategies to produce high quality herbal plants on a large scale.

Medicinal plants are mainly propagated through seeds. Plant propagation via seeds is not efficient due to unavailability of seeds throughout the year and very low germination rates (Dassanayake et al., 2018). Efficient vegetative propagation techniques have not yet been established for most of the medicinal plant species in Sri Lanka. Biotechnological approaches such as plant tissue culture provide tremendous potential and therefore those techniques are becoming more popular for mass scale production of herbal plants as they provide several advantages over conventional methods (Nagahatenna \& Peiris, 2007; Nagahatenna \& Peiris, 2008a; Nagahatenna \& Peiris, 2008b). For instance, only a small amount of explant is needed for the initial culture establishment and large numbers of genetically identical disease-free plants with uniform chemical composition can be produced independent of seasonal variations. Additionally, in vitro techniques also provide greater opportunities to develop new varieties with improved medicinal and ornamental characteristics (Pellegrineschi et al., 1994; Shibata, 2008) through biotechnological approaches. However, one of the major drawbacks which exist for this potential is the lack of efficient tissue culture techniques for native medicinal plant species. This is primarily attributed to the recalcitrant nature of the medicinal plants due to presence of polyphenolic compounds(Sarasan et al., 2006).Therefore, the primary objective of this study was to develop a highly efficient in vitro protocol for Osbeckiaoctandra, one of the extensively used medicinal plants(Perera et al., 2013; Fernando et al., 1990) which also contains unique ornamental characteristics.

\section{Osbeckiaoctandra (L) DC. Amember of family} Melastomatacae is an endemic perennial shrub and it is widespread in the moist mid and low country up to $1500 \mathrm{~m}$ altitude in Sri Lanka (Jayaweera, 1982). Over the past few years, $O$. octandrahas attracted significant scientific attention due to its immense medicinal properties. It is widely used to treat severe non-communicable diseases such as diabetes, cancer, hemorrhoids, and hepatitis (Perera et al., 2013; Fernando et al., 1990; Thabrew et al., 2000; Balasooriya et al., 2020; Prasadani et al., 2021). Beside its medicinal properties, it also possesses high ornamental characteristics. For instance, O.octandrahas has many erect branches with bristly hair reddish brown bark. Leaves are opposite, narrowly lanceolate or oblong lanceolate and contain scattered long hairs beneath. Pale pink or nearly white flowers with round five petals give a more attractive appearance for the plant (Jayaweera, 1982) and therefore, Osbeckiacan be used in landscape horticulture and as an ornamental potted plant.

In Sri Lanka due to rapid industrialization, the natural habitats of this plant species have been threatened and currently O.octandrais is considered as a vulnerable species. In vitro techniques for $O$. octandra and other members in the family of Melastomatacaehave not yet been well established. As a first step towards the development of a more efficient in vitro regeneration system of $O$. octandra, the previously demonstrated novel micropropagation system using nodal 
explants is recommended (Nagahatenna \& Peiris, 2008b). Here another new in vitro system using leaf explants which are the most abundant source materials, is reported.

\section{Materials and Methods}

Adventitious shoot induction from leaf explants

Leaves expanding from in vitro cultured shoots (Nagahatenna \& Peiris, 2008) were excised and cut into approximately 1 $\mathrm{cm}^{2}$ sections. They were cultured in vitro with their abaxial sides on the Murashige and Skoog (1962) (MS) basal medium supplemented with different concentrations of cytokinines $(2,4$ and $6 \mathrm{mg} / \mathrm{L}$ Kinetin and 1,3 and $5 \mathrm{mg} / \mathrm{L} \mathrm{BAP}$ ) in combinations with NAA (0 and $0.5 \mathrm{mg} / \mathrm{L}$ ) and $3 \%$ sucrose, 100 $\mathrm{mg} / \mathrm{L}$ myo-inositol and solidified with $0.8 \%$ agar ( $\mathrm{pH}$ 5.8). The effectiveness of light and dark conditions on the regeneration of leaf explants were evaluated by incubating at $25 \pm 2$ ${ }^{0} \mathrm{C}$ with or without cool fluorescent light (9001500 lux) and 16:8 h (day/night) photoperiod. Performances of the plants were observed at weekly intervals. Explants showing the signs of regeneration were transferred to light 6 weeks after culture initiation and the average shoot length and the numbers of shoots per explant were recorded from 15 biological replicates.

\section{Shoot multiplication and rooting}

When regenerated shoots reached to a height of 0.2 to $0.4 \mathrm{~cm}$, they were individually excised from leaf explants and transferred to vessels containing hormone free MS medium supplemented with high sugar (4\%) content. Cultures were incubated under light conditions described above and were subcultured every month. Performances of the plants were observed at weekly intervals. Average shoot length and the numbers of shoots per explant were recorded at the end of the $4^{\text {th }}$ week.

\section{Acclimatization of the plantlets}

Fully developed plants with $8-10 \mathrm{~cm}$ shoots were transferred to pots containing a sand: soil mixture (2:1) and kept inside a propagator for 2 months at $25{ }^{\circ} \mathrm{C}$ and $12: 12 \mathrm{~h}$ (day/ night) photoperiod.

\section{Data analysis}

The experiments were arranged in a completely randomized design. The effects of BAP and kinetin on shoot length were analyzed using 1-way ANOVA with SAS statistical software. The effect of BAP and kinetin on number of shoots per explant was analyzed by the chi-square contingency test with Minitab. Mean comparisons were done with Duncan's multiple range test (DMRT).

\section{Results and Discussion}

\section{Adventitious shoot induction from leaf explants}

Auxins and cytokinin play major roles in cell division, meristem establishment and root and shoot organogenesis (Hill \& Schaller, 2013). Therefore, in tissue culture systems, elevated levels of auxins and cytokinin are used but the optimum cytokinin to auxin ratio for the induction of organogenic differentiation is largely dependent on the plant species. In order to develop an efficient tissue culture system for O. Octandra, in our study, we cultured leaf explants on solid MS media supplemented with various combinations of cytokinin (BAP and Kinetin) and auxin (NAA) and evaluated their shoot regeneration ability under light and dark conditions. 
We consistently observed that shoot initiation from in vitro leaf explants of O.octandrawas which highly benefited from a period of darkness. Significantly higher shoot induction percentages were observed in leaf explants incubated under dark conditions (Table 1, Figure 1A, B, C). In contrast, among all of the light-incubated explants, shoot induction was detected only with two hormonal treatments (Kinetin $4 \mathrm{mg} / \mathrm{L}$ and $6 \mathrm{mg} / \mathrm{L}$ with $0.5 \mathrm{mg} / \mathrm{L}$ NAA). Light-incubated explants produced a lower number of shoots relative to darkincubated explants and all of them displayed retarded shoot growth (Table 1, Figure 1G). This implies that light incubation at the initial culture establishment stage significantly impacted not only shoot initiation but also subsequent shoot growth. Ithas been previously reported that light conditions promote rapid degradation of auxins in the media relative to dark conditions ( $\mathrm{Gu}$ and Zhang, 2005). Therefore, we speculate that light-incubated explants may have experienced severe shoot inhibition due to low auxin availability. Therefore, it is probable that observed higher shoot growth in dark-incubated explants is a consequence of greater accessibility of cytokinines and auxinsto the growing shoots.

In addition to dark conditions, NAA also seemed to play a crucial role in shoot induction. For instance, $80-100 \%$ of dark-incubated explants generated shoots on MS media supplemented with various concentrations of kinetin alone. However, when Kinetin was added in combination with NAA, only $33-44 \%$ of explants generated shoots (except $6 \mathrm{mg} / \mathrm{L}$ Kinetin) (Table 1). Similarly, the presence of NAA in the BAP supplemented media also severely suppressed shoot induction (except at $3 \mathrm{mg} / \mathrm{L} \mathrm{BAP}$ ).
When dark-incubated explants were transferred to light, shoots turned into green due to accumulation of chlorophyll (Figure $1 \mathrm{E}, \mathrm{F})$ and vigorous shoot production was observed. BAP containing media (both in the presence and absence of NAA), produced the highest number of shoots per explant (Table 1). Application of NAA, facilitated greater shoot production than BAP alone (except $5 \mathrm{mg} / \mathrm{L}$ ). However, when NAA $(0.5 \mathrm{mg} / \mathrm{L})$ was added in combination with varying concentrations of Kinetin (2-6 mg/L), shoot formation was markedly suppressed. Collectively, our results revealed that BAP facilitates shoot growth of $O$. octandra than Kinetin. The best hormonal combination for the production of the highest number of shoots from darkincubated explants was $3 \mathrm{mg} / \mathrm{L} \mathrm{BAP}$ and 0.5 mg/LNAA(Table 1).

\section{Shoot multiplication and rooting}

Shoots regenerated from dark-incubated explants were transferred to the shoot multiplication and rooting media, whereas shoots originated from light-incubated explants were discarded due to retardation of shoot growth.

Elevated levels of cytokinin promoted vigorous shoot and root development (Figure $1 \mathrm{H}, \mathrm{I})$. The number of shoots, number of roots and root length were difficult to measure due to profuse shoot and root growth and therefore, shoot length was evaluated.

Among two different cytokinin tested, BAP was found to be more effective in generating longer shoots (Table 2). 
Table 1.

Induction and growth of shoots of O.octandra on different hormonal combinations 6 weeks after culture establishment

\begin{tabular}{ccccccccc}
\hline & \multirow{2}{*}{ Treatment } & & \multicolumn{2}{c}{$\begin{array}{c}\text { \% of shoot } \\
\text { induction }\end{array}$} & \multicolumn{2}{c}{$\begin{array}{c}\text { Number of shoots/ } \\
\text { explant }\end{array}$} & \multicolumn{2}{c}{ Shoot length (cm) } \\
\hline BAP & Kinetin & NAA & Dark & Light & Dark & Light & Dark & Light \\
\hline- & - & - & - & - & - & - & - & - \\
\hline- & 2 & - & 80 & - & $4.7 \pm 1.5^{\mathrm{a}}$ & - & $1.3 \pm 0.4^{\mathrm{a}}$ & - \\
\hline- & 4 & - & 100 & 25 & $7.6 \pm 2.3^{\mathrm{b}}$ & $1.2 \pm 0.2^{\mathrm{a}}$ & $1.5 \pm 0.6^{\mathrm{a}}$ & $0.6 \pm 0.2^{\mathrm{a}}$ \\
\hline- & 6 & - & 100 & - & $10 \pm 2.4^{\mathrm{c}}$ & - & $1.5 \pm 0.7^{\mathrm{a}}$ & - \\
\hline- & 2 & 0.5 & 33.4 & - & $2 \pm 0.3^{\mathrm{d}}$ & - & $2.1 \pm 0.9^{\mathrm{c}}$ & - \\
\hline- & 4 & 0.5 & 44.5 & - & $5 \pm 0.8^{\mathrm{e}}$ & - & $1.7 \pm 0.5^{\mathrm{a}}$ & - \\
\hline- & 6 & 0.5 & 100 & 33.4 & $9.8 \pm 2.1^{\mathrm{c}}$ & $1.5 \pm 0.6^{\mathrm{a}}$ & $1 \pm 0.1^{\mathrm{b}}$ & $0.4 \pm 0.1^{\mathrm{a}}$ \\
\hline 1 & - & - & 62.5 & - & $15.7 \pm 2.7^{\mathrm{f}}$ & - & $1.2 \pm 0.3^{\mathrm{a}}$ & - \\
\hline 3 & - & - & 72.6 & - & $14.8 \pm 2.1^{\mathrm{f}}$ & - & $0.8 \pm 0.1^{\mathrm{d}}$ & - \\
\hline 5 & - & - & 58.3 & - & $9.6 \pm 1.9^{\mathrm{c}}$ & - & $0.6 \pm 0.2^{\mathrm{d}}$ & - \\
\hline 1 & - & 0.5 & 20.3 & - & $18.7 \pm 3.5^{\mathrm{g}}$ & - & $1 \pm 0.6^{\mathrm{b}}$ & - \\
\hline 3 & - & 0.5 & 92.4 & - & $22.6 \pm 4.7^{\mathrm{h}}$ & - & $1.4 \pm 0.5^{\mathrm{a}}$ & - \\
\hline 5 & - & 0.5 & 40.6 & - & $7.3 \pm 2.4^{\mathrm{b}}$ & - & $0.7 \pm 0.3^{\mathrm{d}}$ & - \\
\hline
\end{tabular}

Note: Data expressed as Mean \pm SE from 15 replicates. Within columns, values followed by the same letter are not significantly different at the $\mathrm{p}=0.05$. 


\section{Figure 1.}

Adventitious shoot formation from the leaf explants of $O$. octandra on MS medium with different hormonal combinations. (A) (B) (C) Shoots regenerated at the leaf margins 6 weeks after culture establishment under dark conditions (D) Very few or no shoot induction under the light conditions 6 weeks after culture establishment (E) (F) Darkincubated leaves 3 weeks after transferring to light (G) Formation of few leaves, 6 weeks post culture establishment from explants continuously incubated under light conditions (H) Dark-incubated explants 6 and (I) 8 weeks after transferring to light.

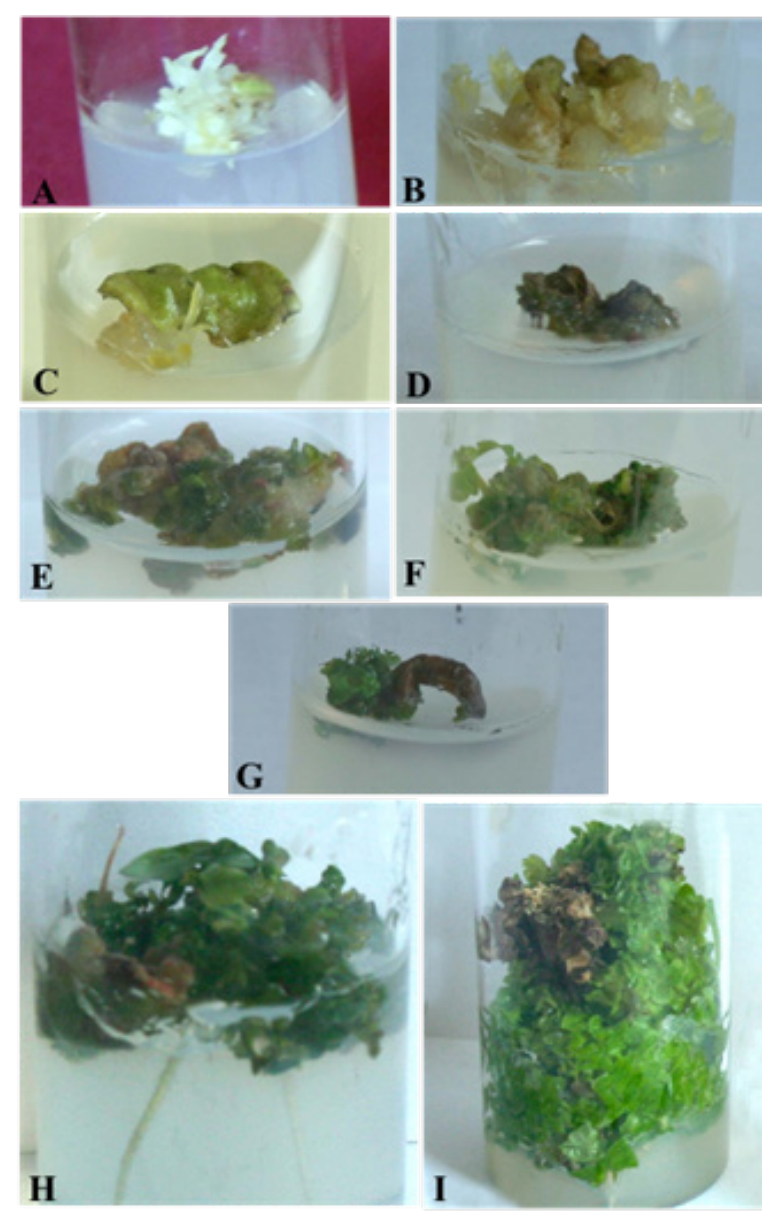

Root system were observed on MS basal medium containing $1 \mathrm{mg} / \mathrm{L} \mathrm{BAP}$ (Figure 2).
Figure 2.

Shoot multiplication and root induction of O.octandra on hormone free MS medium.(B) In vitro rooted plantlets of O.octandraduring acclimatization
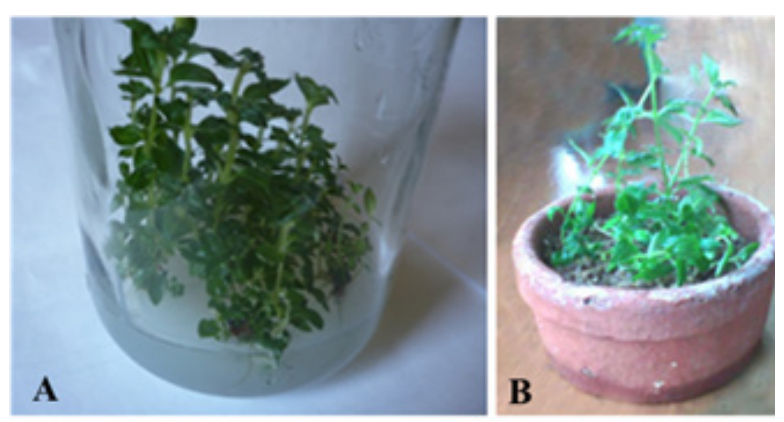

Acclimatization of the plantlets

When rooted plantlets reached to a size of 8-10 $\mathrm{cm}$ on growth regulators free media, they were transferred to pots containing sterile sand: soil (2:1). Eventually, $89 \%$ of regenerated plantlets survived and exhibited similar morphological characters as the mother plants (Figure 2B).

\section{Conclusions}

To the best of our knowledge, this is the first study which demonstrates an in vitro regeneration protocol for $O$. octandra using leaf explants. Our results indicate that higher number (22.6 \pm 4.7 shoot/explant) of true-totype plants can be regenerated by establishing the leaf cultures on MS media supplemented with $3 \mathrm{mg} / \mathrm{L}$ BAP and $0.5 \mathrm{mg} / \mathrm{L}$ NAA under dark conditions. The highest shoot length $(5.98 \pm 1.03 \mathrm{~cm})$ with well-developed root system can be achieved upon transferring onto a MS basal medium with $1 \mathrm{mg} / \mathrm{L}$ BAP. This highly efficient protocol will enable mass production of high quality $O$. octandra plants to fulfil the demand of the pharmaceutical industry. 
Table 2.

Effect of different concentrations of plant growth regulators on shoot multiplication

\begin{tabular}{cccc}
\hline \multicolumn{2}{c}{ Growth regulator concentrations $(\mathrm{mg} / \mathrm{L})$} & Shoot length $(\mathrm{cm})$ \\
\hline BAP & Kinetin & NAA & 0 \\
\hline- & - & - & $3.22 \pm 1.38^{\mathrm{g}}$ \\
\hline- & 2 & - & $3.27 \pm 1.21^{\mathrm{g}}$ \\
\hline- & 4 & - & $2.11 \pm 0.73^{\mathrm{i}}$ \\
\hline- & 6 & - & $2.89 \pm 1.31^{\mathrm{f}}$ \\
\hline- & 2 & 0.5 & $0.81 \pm 0.32^{\mathrm{h}}$ \\
\hline- & 4 & 0.5 & $2.63 \pm 1.04^{\mathrm{f}}$ \\
\hline- & 6 & 0.5 & $5.98 \pm 1.03^{\mathrm{a}}$ \\
\hline 1 & - & - & $5.24 \pm 1.3^{\mathrm{d}}$ \\
\hline 3 & - & - & $4.67 \pm 1.78^{\mathrm{b}}$ \\
\hline 5 & - & - & $4.87 \pm 0.92^{\mathrm{b}}$ \\
\hline 1 & - & 0.5 & $4.47 \pm 1.38^{\mathrm{c}}$ \\
\hline 3 & - & 0.5 & $2.36 \pm 0.91^{\mathrm{e}}$ \\
\hline 5 & - & 0.5 & \\
\hline
\end{tabular}

Note: Data expressed as Mean \pm SE from 15 replicates. Within columns, values followed by the same letter are not significantly different at the $p=0.05$.

It is interesting to note that the presence of NAA in both BAP and Kinetin supplemented media led to the reduction of shoot length (except at $6 \mathrm{mg} / \mathrm{L}$ Kinetin). The shoot length was negatively correlated with BAP concentrations and the longest shoots $(5.98 \pm 1.03 \mathrm{~cm})$ with well-developed

\section{Acknowledgement}

Authors would like to thank Sri Lanka Council for Agricultural Research Policy (CARP) for providing funds for this research.

\section{References}

Balasooriya, M. G. D. N., Karunarathna, W. D. C. K., \& Wickramarachchi, W. J. (2020). Evaluation of the clinical efficacy of HeenBowitiya Leaves [Osbeckiaoctandra] powder in the management of diabetes mellitus. World Journal of Pharmaceutical Research. 9(7): 2541-2547. 
Dassanayake, D. M.I.C.B., Krishnarajah, S.A., \& Eeswara, J. P. (2018). Development of an Effective Propagation Protocol for Osbeckiaoctandra (L.) DC. (HeenBovitiya). Tropical Agricultural research, 29(2):123-134.

Fernando, M. R., Thabrew, M. I., \& Karunanayake, E. H. (1990). Hypoglycaemic activity of some medicinal plants in Sri Lanka. Gen. Pharmac. 21(5): 779-782.

Gu, X. F. \& Zhang, J. R. (2005). An efficient adventitious shoot regeneration system for Zhanhua winter jujube (Zizyphus jujube Mill.) using leaf explants. Plant Cell Rep. 23:775-779.

Hill, K. \& Schaller, G. E. (2013). Enhancing plant regeneration in tissue culture. Plant Signaling and Behaviour. 8(80): e25709.

Jayaweera, D. M. A. (1982). Medicinal plants (Indigenous and exotic) used in Ceylon. Part IV. The national Science Council of Sri Lanka, Colombo.46-47.

Murashige, T. \& Skoog, F. (1962). A revised medium for rapid growth and bioassay with tobacco tissue cultures.Physiol Plant. 15:473-497.

Nagahatenna, D. S. K. \& Peiris, S. E. (2007). In vitro propagation of Hemidesmus indicus (L.) R. Br. (Iramusu) through nodal culture. Tropical Agricultural Research. 19: 181-192.
Nagahatenna, D. S. K. \& Peiris, S. E. (2008). Modification of plant architecture of Hemidesmus indicus (L.) R. Br. (Iramusu) by in vitro colchicine treatment. Tropical Agricultural Research. 20: 234-242.

Nagahatenna, D. S. K. \& Peiris, S. E. (2008). In vitro micropropagation of OsbeckiaOctandra (L) Dc. (HeenBovitiya) through single nodal culture. Proceedings of National Symposium on Floricultural Research of Sri Lanka.

Napagoda, M. T., Sundarapperuma, T., Fonseka,D.,Amarasiri, S., \& Gunaratna, P. (2018). An Ethnobotanical Study of the Medicinal Plants Used as AntiInflammatory Remedies in Gampaha District, Western Province, Sri Lanka. Scientifica. 2018.

Napagoda, M. T., Sundarapperuma, T., Fonseka, D., Amarasiri, S., \& Gunaratna, P. (2019). Traditional Uses of Medicinal Plants in Polonnaruwa District in North Central Province of Sri Lanka. Scientifica. 2019.11.

Pellegrineschi, A., Damon, J., Valtorta, N., Paillard, N., \& Tapfer, D. (1994). Improvement of Ornamental Characters and Fragrance Production in Lemonscented Geranium through Genetic Transformation by Agrobacterium rhizogenes. Nature. 12, 64-68.

Perera, P. R. D., Ekanayake, S., \& Ranaweera, K. K. D. S.(2013). In vitro study on antiglycation activity, antioxidant activity and phenolic content of 
Osbeckiaoctandra L. leaf decoction. JPP, 2(4): 158-161.

Prasadani, M., Bogahawaththa, S., Illeperuma, R. P., \& Kodithuwakku, S. P. (2021). Leaf Extract of Osbeckiaoctandra L. (HeenBovitiya) Suppresses Human Oral Squamous Cell Carcinoma Cells Migration and Induces Cellular DNA Damage. Journal of Oral and Maxillofacial Surgery, Medicine, and Pathology. 33(2): 215-220.

Sarasan, V., Cripps, R., Ramsay, M. M., Atherton, C., McMichen, M., Prendergast, G., Rowntree, \& J. K. (2006). Conservation in vitro of threatened plants- progress in the past decade. In vitro cell. Dev. Biol. 42: 206-214.

Shibata, M. (2008). Importance of genetic transformation in ornamental plant breeding. Plant Biotechnology. 25(1): 3-8.

Thabrew, M. I. (2000). Investigation of Hepatoprotection by HeenBovitiya Proc. SLAAS 56 ${ }^{\text {th }}$ Annual Sessions. 9-13. 